\title{
The Foundation for Environmental Conservation
}

$F_{a}^{o l}$ ollowing is the President's Report for the Year 1994, approved unanimously at the Foundation's 20th Annual General Meeting at its Headquarters on 16 June 1995, and duly updated, with items reported in the preceding year's sequence:

1. Environmental Conservation:- In its twenty-first year of publication we continued to receive ample material - especially longer papers - to maintain all sections of our quarterly Journal well up to standard. We published 21 items (including mere notices etc.) in the Editorial Section, again 31 main papers, 18 Short Communications, 35 Notes, News \& Comments, 20 Reports on Conferences \& Meetings with, terminating the same section, 12 notices of Important Prospects, and 23 Book Reviews with, at the end of that section, 8 Book Notices. Thus in this latest volume of our Journal were published in all 158 separately-headed items which were usually signed by their Authors and almost all original, on a vast range of often leading environmental and/or conservational topics with some 120 illustrations and 90 tables. Requests for reprinting permission continued to be numerous and almost always granted, with occasional receipt of royalties when reprinting was to be in widely-for-sale books. A final supplement of the Index of Titles and Authors is contemplated after completion of the 22 nd year and volume of the Journal which to a substantial extent should exemplify the development of the environment/ conservation movement.

2. International Conferences on Environmental Future:The Proceedings book on the fourth and last of these has been well received, Dr Norman Myers terminating his review by claiming for it that it '... warrants a place on the desk, not the library shelf, of every political leader and policymaker. If the three earlier conference books in the series had enjoyed such exposure, there might well have been less need for this fourth concerning The Biosphere's prospects of survival.'

3. World Council For The Biosphere:- Retained to take care of some continuing and foreseeable needs on desiderata such as those mentioned under item 6 below.

4. Environmental Monographs \& Symposia and Cambridge Studies in Environmental Policy:- The former of these has been discontinued but the latter is being revived at the publishers' insistence, so that several promising items are now on the way.

5. World Who Is Who and Does What in Environment \& Conservation:- Helped by a grant from the Sasakawa Foundation, work proceeded apace on this throughout the past year so that the first edition, containing some 1,250 biographies, is now going to the printer and should be available early in 1996 in film and/or disk form for a suitable distributor — failing which we'll handle orders ourselves through our helpful printer. To date we have requests for about 650 copies. A special feature of this long-awaited compilation is the detailed second Appendix indicating, under the very numerous subject-headings, who 'Does What'. Two further, cumulative editions are envisaged for the future - hopefully to surpass our original prospect of 3,000 biographies. All biographees have been approved by the Foundation's confidential Awards Committee.
6. Biosphere Day and Supporting Activities:-As a yearly reminder of what humanity needs to take care of above all else, namely The Biosphere as its own and Nature's sole life-support, Biosphere Day was celebrated again on 21 September 1994 it is hoped on all normallyinhabited continents. This was done merely through associates and correspondents, as the time is still awaited when it should be possible to organize matters more forcibly and with full publicity. Biosphere Day comes at an appropriate time-gap following the springtime Earth Day and the early June Environment Day, and is planned to be supported by an endowment fund that should be sufficient to cover the annual award of a major Biosphere Prize and about six satellite prizes for advances in the main branches of scientific or allied endeavour involved - with due recognition not only of past achievement but also giving support to encourage ongoing work.

7. Best Paper Prize(s):- - The Awards Committee having been asked to take into consideration the contributors to our Environmental Challenges as well as those to Environmental Conservation, had not yet completed their report at the time of the Meeting. It is, however, gratifying to note how often, in editing our World Who Is Who..., we have come across mention of the Prize by former winners, indicating its esteemed status despite its modest size. |As indicated on page 102 of our Summer issue, the choice was again of 4 papers.].

8. Encouraged Associates:- (i) The Vernadsky International Centre for Biosphere Studies has continued to operate from Pushchino, near Moscow, Russia, which it is striving with others to make into a major Centre of 'green movement', environmental conservation, ecological investigation, and other relevant activities; (ii) The Foundation for Environmental Awareness has been finally established in 1994 in Baroda, India - set up around the International Society of Naturalists' (INSONA's) quarterly Journal, Environmental Awareness, in much the same manner as our own FEC started officially in 1975 , it has comparable objectives to the latter and is to be welcomed warmly as a 'kindred spirit'; similarly to be encouraged whenever possible are (iii) (INSONA of which the undersigned is a VicePresident), and (iv) The International Energy Foundation (IEF), of which an account is published on page 276 of this issue.

9. Environmental Challenges:- Of the second of these original paperback readers by leaders', entitled $P$ opulation and Global Security, a 'Limited Geneva Edition' (for the United Nations Population Fund and others) was published in time for the UN International Conference on Population and Development, which took place in Cairo, Egypt, in September 1994. The advances in worldwide understanding on concensus achieved at the latter event were such that the Cambridge University Press are commissioning an updated World Edition to be edited by the undersigned, though the decision has yet to be taken as to whether it will be published in the Cambridge Studies on Environmental Policy series or separately. In any case it is decided to continue our Foundation's series of Environmental Challenges, for which there are plentiful suggestions or at least ideas. 
10. Major Prizes Needed:- Our initiative to have peace with the environment recognized as a theme for the Nobel Peace Prize was continued under the latest deadline for nominations, and there have been further unofficial talks about the desirability of a separate prize for ecology and/or conservation. Fortunately some other major awards are available to help relieve the current very serious shortage of funds for environmental work, and we hope soon to be in a position at last to seek actively the necessary wherewithal for the Biosphere Prizes mentioned in 6 (above).

\section{Nicholas POLUNIN}

4 June 1995 (updated on 15 October)

\section{Biosphere Day 1995 \\ (Celebrated each Year on September 21st*)}

There are a few things that I fecl should be said by way of explanation and exhortation on this Fifth celebration of Biosphere Day. The first is that humanity's perception of its surroundings has long benefited - especially in North America - from the holding of an Earth Day, falling in the Spring, and possessed I understand of a large budget to awaken people widely to some of the problems that our only known life-supporting Planet Earth faces. We have also had for some years the summer Environment Day usually on June 5th - which is the occasion of the bestowal of its most prestigious awards by the United Nations Environment Programme. And now - well spaced into the presaging of the Autumn Solstice in the Northern Hemisphere and of course the Spring Solstice in the Southern Hemisphere - we have Biosphere Day, which is designed to remind all humanity, annually on this date, of its quintessential imperative that surely is to safeguard The Biosphere above all elsc. For The Biosphere is the relatively fragile - some say doomed - life-supporting sphere around the rest of our far-more-solid Planet Earth, and is our own and all Nature's sole home and entire life-support apart from energy from the Sun.

Without The Biosphere we and our descendents cannot hope to exist, so clearly it is this Biosphere which we should take care of as our foremost responsibility. Moreover, to quote from an editorial in Environmental Conservation 'we humans have the unique responsibility, ultimately to the entire Universe, of safeguarding life; for it now seems that there is nowhere else that life exists in, and emanates from, than Earth's Biosphere, which it is still

\footnotetext{
* Message sent to supporters on all inhabited continents, adjuring them to celebrate Biosphere Day in however modest a way.
}

surely in our own but no other living thing's power to safeguard and preserve.'

We believe, too, that Humankind now has, in everextending plenty, the scientific knowledge and means of saving its world. But at present the public recognition and the will and full resolve are lacking, people with rare exceptions being interested only in their own environments, though realization of the need to think and act globally is beginning to spread. That is what Biosphere Day is striving to further, helped in due course we hope by a supporting Fund and aspired-for Biosphere Prizes. These intended awards are to be for demonstrated ad hoc leadership, and we hope that at least one will be substantial enough each year to enable recipients to continue pertinently valuable work, while other, satellite ones should be for advances in component topics and provide real encouragement to recipients to continue their chosen work of ultimate benefit to The Biosphere. There are also starting in several countries supportive Biosphere Clubs - autonomous but under the auspices of our Foundation, and ultimately we hope forming a global network in the manner of Lions and Rotary Clubs.

So have a happy and ecologically beneficial Biosphere Day, spread our gospel as effectively and widely as you can, and let us all keep in touch ${ }^{\dagger}$ with developments and help to guide them in the best direction for The Biosphere's benefit.

\section{NichOlas Polunin} 7 September 1995

${ }^{\dagger}$ Destined to be far easier from this end as of early next year when I will have relinquished the rather exacting and certainly timeconsuming sole editorship of my last international Journal, Environmental Conservation. - N.P.

\section{Survey of Global Environmental Issues Conducted by the Asahi Glass Foundation}

$\mathrm{T}$ he Asahi Glass Foundation has conducted a survey by means of a questionnaire on global environmental issues every year since the 'Earth Summit' was held in Rio de Janeiro in 1992. Although international interest in, and enthusiasm for, environmental issues may seem to have waned since then, we do believe that substantial and steady progress in protecting the environment has been made in many countries.

This year, 2,656 questionnaires were mailed in April to specialists world-wide in both governmental and nongovernmental organizations that are listed in our environmental database, and 576 were returned by the end to July - a response-rate of $22 \%$.

The following are the key findings of the 1995 survey: 1. Humanity in Crisis - Today and 50 Years into the Future:- Although the average level of concern for all respondents in 1995 was virtually unchanged from that of
1994, large changes within regions could be detected. In particular, Eastern Europe and the former Soviet Union and Oceania showed a heightened sense of crisis. On the other hand, the sense of crisis in Western Europe and the United States and Canada diminished.

In general, respondents felt that the state of the global environment in 50 years would be worse than conditions today. However, responses from developing regions were optimistic.

2. Lifestyle Changes:- Respondents from regions such as the United States and Canada, Latin America, and Western Europe; showed a strong recognition of the need to adapt to a more frugal lifestyle.

3. Progress on Environmental Issues since the 'Earth Summit':- This year, the accomplishments of NGOs, local governments, and citizens' groups, were again valued 